www.mdpi.com/journal/marinedrugs

Article

\title{
Solwaric Acids A and B, Antibacterial Aromatic Acids from a Marine Solwaraspora sp.
}

\section{Gregory A. Ellis ${ }^{1, \dagger}$, Thomas P. Wyche ${ }^{1, \dagger}$, Charles G. Fry ${ }^{2}$, Doug R. Braun ${ }^{1}$ and Tim S. Bugni ${ }^{1, *}$}

1 Pharmaceutical Sciences Division, University of Wisconsin-Madison, 777 Highland Avenue, Madison, WI 53705, USA; E-Mails: gaellis@wisc.edu (G.A.E.); twyche@wisc.edu (T.P.W.); drbraun1@facstaff.wisc.edu (D.R.B.)

2 Department of Chemistry, University of Wisconsin-Madison, 1101 University Avenue, Madison, WI 53706, USA; E-Mail: fry@chem.wisc.edu

$\dagger$ These authors contributed equally to this work.

* Author to whom correspondence should be addressed; E-Mail: tbugni@pharmacy.wisc.edu; Tel.: +1-608-263-2519; Fax: +1-608-262-5345.

Received: 19 December 2013; in revised form: 24 January 2014 / Accepted: 24 January 2014 / Published: 14 February 2014

\begin{abstract}
Two novel trialkyl-substituted aromatic acids, solwaric acids A and B, were isolated from a marine Solwaraspora sp. cultivated from the ascidian Trididemnum orbiculatum. Solwaric acids A and B were isotopically labeled with $\mathrm{U}_{-}{ }^{13} \mathrm{C}$ glucose, and analysis of a ${ }^{13} \mathrm{C}-{ }^{13} \mathrm{C}$ COSY allowed for unambiguous determination of the location of the phenyl methyl group. The two novel compounds demonstrated antibacterial activity against methicillin-resistant Staphylococcus aureus (MRSA) and methicillin-sensitive Staphylococcus aureus (MSSA).
\end{abstract}

Keywords: Trididemnum orbiculatum; Solwaraspora; methicillin-resistant Staphylococcus aureus

\section{Introduction}

Infectious disease continues to be a major issue, as it is the second leading cause of death worldwide [1]. Complicating the treatment of infectious disease is antibiotic resistance, which results in about $\$ 20$ billion in health service costs and at least 23,000 deaths in the United States per year [2,3]. Among antibiotic resistant bacteria, methicillin-resistant Staphylococcus aureus (MRSA) 
has become a major concern for human health [4-8]. While the mortality percentages in methicillin-susceptible Staphylococcus aureus (MSSA) patients range from 5\% to $28 \%$, the mortality percentages for MRSA patients tend to be even higher, ranging from $10 \%$ to $64 \%$ [5-8]. Although ranging between studies, one study encompassing data from different European countries found an additional $80 \%$ excess mortality rate at day 30 after infection was contributed by methicillin resistance in $S$. aureus $[5,6,8]$. Therefore, antibiotic resistance escalates the importance for discovering new and effective antibiotics in an efficient manner.

In our pursuit of novel antibacterial compounds, we isolated two novel aromatic acids that were named solwaric acids A (1) and B (2) and the known 2,4,6-triphenyl-1-hexene (3) [9-11], from a marine Solwaraspora sp. (Strain WMMB329) cultivated from the ascidian Trididemnum orbiculatum (Van Name, 1902) [12]. To our knowledge, these are the first novel compounds reported from a Solwaraspora sp., although strain WMMB329 also showed 99\% 16S rDNA sequence similarity to some Micromonospora spp. Solwaric acids A (1) and B (2) demonstrated antibacterial activity against methicillin-resistant Staphylococcus aureus (MRSA) and methicillin-sensitive Staphylococcus aureus (MSSA). Aromatic acids are somewhat rare in natural products, with most being produced by actinomycetes [13-16].

Although the solwaric acids did not present elucidation challenges typical of some natural products, such as few protons, the aromatic ring was substituted only with carbon-based substituents. As a result, the chemical shifts of the protons presented challenges with respect to unambiguously determining the location of the methyl group. HMBC correlations were not conclusive and ${ }^{13} \mathrm{C}$ calculations using density functional theory were questionable due to the small differences between two potential structures. Therefore, solwaric acids A (1) and B (2) were isotopically enriched with $\mathrm{U}_{-}{ }^{13} \mathrm{C}$ glucose, which allowed for acquisition of a ${ }^{13} \mathrm{C}-{ }^{13} \mathrm{C}$ COSY and unambiguous assignment of the aromatic methyl group location. While the gCOSY requires isotopic enrichment, the method is still economically feasible, and can be made even more so by the use of ${ }^{13} \mathrm{C}$-optimized cryoprobes, which drastically reduce the amount of compound needed and therefore the amount of $\mathrm{U}_{-}{ }^{13} \mathrm{C}$ glucose required. We have more broadly explored the ${ }^{13} \mathrm{C}$ gCOSY as a rapid route for establishing carbon connectivity, and it appears broadly useful for a broad range of bacterially produced natural products. Overall, we have found this method to be highly promising.

\section{Results and Discussion}

\subsection{Bacterial Strain Selection and Structure Elucidation}

Strain WMMB329 was investigated due to the lack of chemistry described in the literature from Solwaraspora spp. as well as antibacterial activity from initial screening of a crude extract. After fermentation and isolation of the bioactive compounds, WMMB329 was found to produce solwaric acids A (1) and B (2), as well as the known 2,4,6-triphenyl-1-hexene (3) (Figure 1). 
Figure 1. Structures of $\mathbf{1}-\mathbf{3}$.

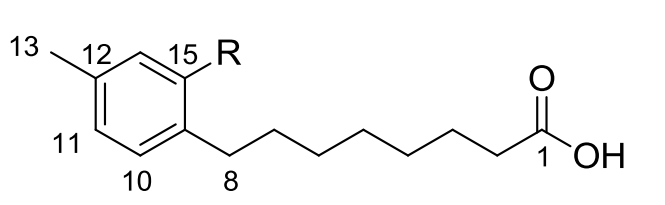

1: $\overbrace{2}^{16} \overbrace{17}^{18}$

2:<smiles>C=C(CC(CCc1ccccc1)c1ccccc1)c1ccccc1</smiles>

HRMS supported the molecular formula of $\mathrm{C}_{18} \mathrm{H}_{26} \mathrm{O}_{2}$ for both solwaric acid A (1) and B (2). The structures of solwaric acids A (1) and B (2) were determined by analysis of ${ }^{1} \mathrm{H}$ and ${ }^{13} \mathrm{C}$ NMR data (Table 1, Supplementary Figures S1-S16). Since the assignment of solwaric acid A (1) and B (2) was confirmed by direct ${ }^{13} \mathrm{C}-{ }^{13} \mathrm{C}$ correlation experiments, the discussion of elucidation has been eliminated with the exception of the olefin at C-16 and C-17 in solwaric acid B (2), which was determined to be $Z$ based on the vicinal coupling constant $\left({ }^{3} J_{\mathrm{H}} 11.4\right)$ [17]. The presence of a methyl group (C-13) attached to the phenyl ring was indicated by HMBC correlations to three aromatic carbon atoms, but it could not be determined unambiguously relative to the other aromatic carbons. The major problem was that two protons in the aromatic ring ( $\mathrm{H}-11$ and $\mathrm{H}-14)$ were at nearly identical chemical shifts. Additionally, C-9 and C-15 were at nearly identical chemical shifts. Therefore, the HMBC correlations supported two possible arrangements for $\mathrm{C}-10$ through $\mathrm{C}-14$ relative to positions 9 and 15 . To further complicate matters, the close chemical shifts of $\mathrm{H}-11$ and $\mathrm{H}-14$ made it difficult to justify assignment based on NOE. Finally, DFT calculations showed differences in the calculated ${ }^{13} \mathrm{C}$ shifts that were within what we have observed as typical experimental error (i.e., not overly conclusive). Direct ${ }^{13} \mathrm{C}-{ }^{13} \mathrm{C}$ correlations, however, would solve the problem. Consequently, we evaluated the use of ${ }^{13} \mathrm{C}$-labeling of the two compounds using $\mathrm{U}-{ }^{13} \mathrm{C}$ glucose and subsequent acquisition of a ${ }^{13} \mathrm{C}-{ }^{13} \mathrm{C}$ gCOSY to address this issue.

Table 1. ${ }^{1} \mathrm{H}$ and ${ }^{13} \mathrm{C}$ NMR data for 1 and $2\left(600 \mathrm{MHz}\right.$ for ${ }^{1} \mathrm{H}, 150 \mathrm{MHz}$ for $\left.{ }^{13} \mathrm{C}, \mathrm{CDCl}_{3}\right)$.

\begin{tabular}{|c|c|c|c|c|c|c|}
\hline \multirow{2}{*}{ Position } & \multicolumn{2}{|c|}{1} & \multicolumn{2}{|c|}{2} & \multirow{2}{*}{ COSY } & \multirow{2}{*}{ НМВС } \\
\hline & $\delta_{\mathrm{C}}$, mult. & $\delta_{\mathrm{H}}(J$ in $\mathrm{Hz})$ & $\delta_{\mathrm{C}}$, mult. & $\delta_{\mathrm{H}}(J$ in $\mathrm{Hz})$ & & \\
\hline 1 & 180.1, C & & $180.5, \mathrm{C}$ & & & \\
\hline 1-OH & & & & $9.34, \mathrm{~s}$ & & \\
\hline 2 & $34.4, \mathrm{CH}_{2}$ & $2.33, \mathrm{t}(6.6)$ & $34.8, \mathrm{CH}_{2}$ & $2.29, \mathrm{t}(6.6)$ & 3 & 3,4 \\
\hline 3 & $24.9, \mathrm{CH}_{2}$ & $1.60, \mathrm{~m}$ & $25.0, \mathrm{CH}_{2}$ & $1.59, \mathrm{~m}$ & 2,4 & 2,4 \\
\hline 4 & $29.2, \mathrm{CH}_{2}$ & $1.30, \mathrm{~m}$ & 29.3, $\mathrm{CH}_{2}$ & $1.30, \mathrm{~m}$ & 3 & \\
\hline 5 & $29.4, \mathrm{CH}_{2}$ & $1.30, \mathrm{~m}$ & $29.4, \mathrm{CH}_{2}$ & $1.30, \mathrm{~m}$ & & \\
\hline 6 & $29.9, \mathrm{CH}_{2}$ & $1.30, \mathrm{~m}$ & $29.6, \mathrm{CH}_{2}$ & $1.30, \mathrm{~m}$ & 7 & \\
\hline 7 & $31.3, \mathrm{CH}_{2}$ & $1.51, \mathrm{~m}$ & $30.9, \mathrm{CH}_{2}$ & $1.48, \mathrm{~m}$ & 8 & 9 \\
\hline 8 & $32.5, \mathrm{CH}_{2}$ & $2.52, \mathrm{t}(7.6)$ & $33.2, \mathrm{CH}_{2}$ & $2.50, \mathrm{t}(7.6)$ & 7 & $6,9,10$ \\
\hline
\end{tabular}


Table 1. Cont.

\begin{tabular}{|c|c|c|c|c|c|c|}
\hline 9 & $137.9, \mathrm{C}$ & & $138.1, \mathrm{C}$ & & & \\
\hline 10 & $129.4, \mathrm{CH}$ & $7.02, \mathrm{~d}(7.2)$ & $129.0, \mathrm{CH}$ & $7.04, d(7.2)$ & 11 & 8,12 \\
\hline 11 & 127.2, $\mathrm{CH}$ & $6.95, d(7.2)$ & 127.6, $\mathrm{CH}$ & $6.96, d(7.2)$ & 10 & 14 \\
\hline 12 & $135.5, \mathrm{C}$ & & 134.7, C & & & \\
\hline 13 & $21.2, \mathrm{CH}_{3}$ & $2.27, \mathrm{~s}$ & $21.2, \mathrm{CH}_{3}$ & $2.30, \mathrm{~s}$ & & $11,12,14$ \\
\hline 14 & $130.4, \mathrm{CH}$ & $6.94, \mathrm{~s}$ & $130.3, \mathrm{CH}$ & $6.97, \mathrm{~s}$ & & 9,13 \\
\hline 15 & $137.5, \mathrm{C}$ & & $136.1, \mathrm{C}$ & & & \\
\hline 16 & $37.2, \mathrm{CH}_{2}$ & 3.33, br d (6.4) & $129.1, \mathrm{CH}$ & 6.47, br d (11.4) & 17 & $12,14,18$ \\
\hline 17 & 137.7, $\mathrm{CH}$ & $\begin{array}{c}5.93, \text { tdd } \\
(6.4,10.1,16.9)\end{array}$ & $126.9, \mathrm{CH}$ & $\begin{array}{c}5.77, \mathrm{dq} \\
(11.4,7.0)\end{array}$ & 16,18 & 18 \\
\hline \multirow[t]{2}{*}{18} & 115.7, $\mathrm{CH}_{2}$ & $\begin{array}{c}5.04, \mathrm{tdd} \\
(1.7,1.7,10.1)\end{array}$ & $14.6, \mathrm{CH}_{3}$ & $1.71, \mathrm{dd}(1.8,7.0)$ & 17 & 16,17 \\
\hline & & $\begin{array}{c}5.00, \text { tdd } \\
(1.7,1.7,16.9)\end{array}$ & & & & \\
\hline
\end{tabular}

\section{2. ${ }^{13} \mathrm{C}-{ }^{13} \mathrm{CgCOSY}$}

NMR experiments, such as the 2D INADEQUATE, have been used for direct determination of carbon-carbon connectivity within natural products [18,19]. Even with cryoprobes, the INADEQUATE can present difficulties due to sample solubility since it requires a fairly concentrated sample. Therefore, we decided to evaluate a ${ }^{13} \mathrm{C}-{ }^{13} \mathrm{C}$ gCOSY, which would require a shorter minimum phase cycle than the INADEQUATE, could be easily implemented, and could be easily interpreted. In particular, calculations suggested that the standard two-pulse gCOSY implemented on NMR spectrometers for ${ }^{1} \mathrm{H}$ experiments could be used for ${ }^{13} \mathrm{C}-{ }^{13} \mathrm{C}$ with no modifications to the pulse program. In fact, after adjusting for ${ }^{13} \mathrm{C}$ and spectral widths, a theoretical sampling of coupling constants in the range 30 to $60 \mathrm{~Hz}$ would produce maximum polarization transfer at 33 to $17 \mathrm{~ms}$, respectively. Additionally, $\mathrm{S} / \mathrm{N}$ for $J_{\mathrm{CC}}=60 \mathrm{~Hz}$ would be maximized with 450 increments - though smaller values (e.g., 256) could be used without much loss in sensitivity-resulting in the 2D resolution of $0.55 \mathrm{ppm}$ (Supplementary Figure S17). The combination of easily optimizing for a range of ${ }^{13} \mathrm{C}-{ }^{13} \mathrm{C}$ coupling constants combined with the fact that the gCOSY does not require ${ }^{13} \mathrm{C}$ inversion pulses and that the experiment could be immediately implemented by others with no requirement for pulse programming made the simple gCOSY an encouraging prospect (Supplementary Figures S18 and S19). The only drawback was that the ${ }^{13} \mathrm{C}-{ }^{13} \mathrm{C} \mathrm{COSY}$ experiment requires isotopic enrichment. To address this problem, we tested the feasibility of ${ }^{13} \mathrm{C}$ incorporation of microbial-derived natural products in conjunction with evaluating the feasibility of the ${ }^{13} \mathrm{C}-{ }^{13} \mathrm{C}$ gCOSY.

To increase the ${ }^{13} \mathrm{C}$ abundance, fermentation of WMMB329 in 1 L ASW-A using uniformly ${ }^{13} \mathrm{C}$-labeled glucose (10 g/L ASW-A) and subsequent purification yielded solwaric acids A (1) and $\mathrm{B}$ (2) with about $35 \%{ }^{13} \mathrm{C}$ incorporation (as evidenced by MS isotopic distribution). The ${ }^{13} \mathrm{C}-{ }^{13} \mathrm{C}$ gCOSY (Figure 2) was acquired in two hours on $18 \mu$ moles $(105 \mu \mathrm{M})$ solwaric acid A (1) and allowed for the methyl group $(\mathrm{C}-13)$ to be unambiguously assigned as attached to $\mathrm{C}-12$; likewise, ${ }^{13} \mathrm{C}-{ }^{13} \mathrm{C}$ COSY correlations were seen between $\mathrm{C}-12$ and $\mathrm{C}-14$, as well as $\mathrm{C}-14$ and $\mathrm{C}-15$. Analysis of the ${ }^{13} \mathrm{C}-{ }^{13} \mathrm{C}$ COSY also confirmed the carbon connectivity throughout the rest of the structure 
(Supplementary Figure S20). While the ${ }^{13} \mathrm{C}-{ }^{13} \mathrm{C}$ gCOSY was acquired on $5 \mathrm{mg}$ of solwaric acid A (1), the experiment can be effectively acquired at considerably lower concentrations. The exact concentration is dependent on the level of ${ }^{13} \mathrm{C}$ incorporation and the spectrometer used, but our initial studies suggest that a ${ }^{13} \mathrm{C}-{ }^{13} \mathrm{C}$ gCOSY can be effectively acquired on low $\mu \mathrm{M}$ concentrations in less than $24 \mathrm{~h}$.

Figure 2. ${ }^{13} \mathrm{C}-{ }^{13} \mathrm{C}$ COSY of ${ }^{13} \mathrm{C}$-labeled 1 .

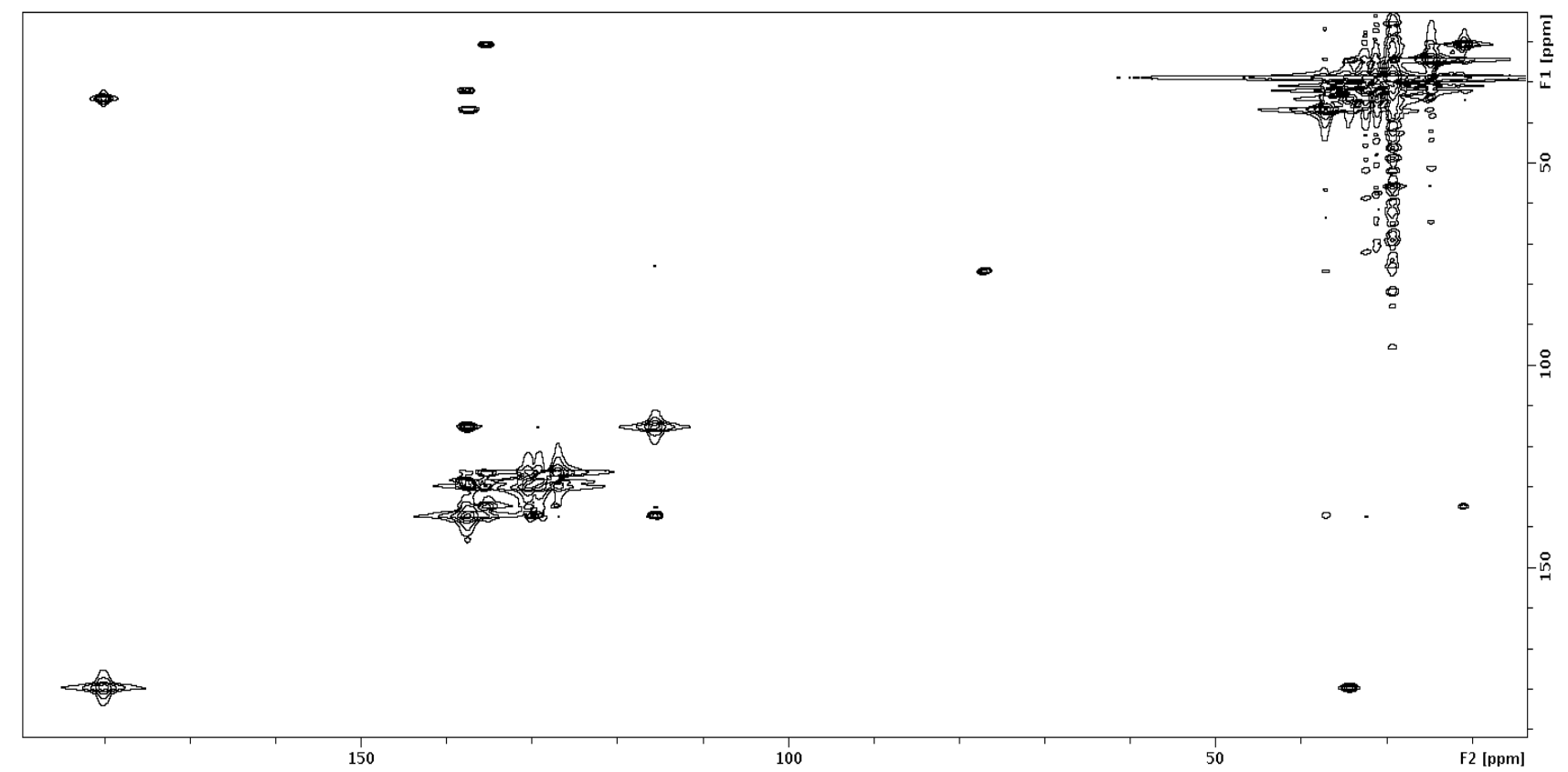

We have also tested to see if this approach would be more broadly applicable to other types of natural products. For example, we have produced two novel ${ }^{13} \mathrm{C}$-labeled peptides from marine-derived bacteria, the structures of which will be reported in a subsequent publication. For complicated structures, this method will drastically reduce elucidation time, which is currently a bottleneck in natural products discovery. Also, recent work by Williamson and Martin has shown that ${ }^{13} \mathrm{C}-{ }^{13} \mathrm{C}$ coupling constants can aid in establishing configuration [20]. Even modest levels of ${ }^{13} \mathrm{C}$ incorporation would be helpful to apply ${ }^{13} \mathrm{C}-{ }^{13} \mathrm{C}$ coupling constants for help in structure elucidation.

Additionally, ${ }^{13} \mathrm{C}$-labeling and acquisition of a ${ }^{13} \mathrm{C}-{ }^{13} \mathrm{C}$ COSY can be useful for analyzing crude extracts or mixtures of compounds. We have demonstrated this approach by acquiring a ${ }^{13} \mathrm{C}-{ }^{13} \mathrm{C}$ $\mathrm{COSY}$ on the extract from the $\mathrm{CHCl}_{3}$ partition of WMMB329 (Supplementary Figure S21). $\mathrm{The}^{\mathrm{CHCl}} \mathrm{H}_{3}$ partition was the first step of purification of the crude extract, and therefore, contained a mixture of compounds. Acquisition of the ${ }^{13} \mathrm{C}-{ }^{13} \mathrm{C}$ COSY on ${ }^{13} \mathrm{C}$-labeled extract allows for separation of the chemistry on a large sweep width ( 200 ppm) and elimination of most media components — which are unlabeled-from the spectrum. Although there may still be a mixture of several labeled compounds, this method could rapidly provide carbon-carbon connectivity for portions of the structures, which could be helpful for dereplication. Therefore, ${ }^{13} \mathrm{C}$-labeling of natural products can be a valuable tool for structure elucidation, as well as other areas of natural product research. 


\subsection{Biological Activity}

Solwaric acids A (1) and B (2) showed antibacterial activity and were more potent against gram positive bacteria (Table 2). Vancomycin and gentamicin were used as a positive control in assays with gram positive and gram negative bacteria, respectively. The known 2,4,6-triphenyl-1-hexene (3) (Supplementary Figures S22-S24) demonstrated no antibacterial activity.

Table 2. Minimum Inhibitory Concentration $(\mu \mathrm{g} / \mathrm{mL})$ of $\mathbf{1}-\mathbf{3}$.

\begin{tabular}{ccccc}
\hline & MRSA & MSSA & E. coli & P. aeruginosa \\
\hline $\mathbf{1}$ & 32 & 64 & 128 & 128 \\
$\mathbf{2}$ & 32 & 64 & 128 & 128 \\
$\mathbf{3}$ & $>128$ & $>128$ & $>128$ & $>128$ \\
\hline
\end{tabular}

\section{Experimental Section}

\subsection{General Experimental Procedures}

Optical rotations were measured on a Perkin-Elmer 241 Polarimeter. UV spectra were recorded on an Aminco/OLIS UV-Vis spectrophotometer. IR spectra were measured with a Bruker Equinox 55/S FT-IR spectrophotometer. NMR spectra were obtained in $\mathrm{CDCl}_{3}$ with a Bruker Avance $600 \mathrm{MHz}$ spectrometer equipped with a $1.7 \mathrm{~mm}{ }^{1} \mathrm{H}\left\{{ }^{13} \mathrm{C} /{ }^{15} \mathrm{~N}\right\}$ cryoprobe, a Bruker Avance $500 \mathrm{MHz}$ spectrometer equipped with a ${ }^{13} \mathrm{C} /{ }^{15} \mathrm{~N}\left\{{ }^{1} \mathrm{H}\right\}$ cryoprobe, and a Varian Unity-Inova $500 \mathrm{MHz}$ spectrometer. HRMS data were acquired with a Bruker MaXis ${ }^{\text {TM }}$ 4G QTOF mass spectrometer. RP HPLC was performed using a Shimadzu Prominence HPLC system and a Phenomenex Luna C18 column $(250 \times 10 \mathrm{~mm}, 5 \mu \mathrm{m})$, as well as a Gilson Preparative HPLC and Phenomenex Gemini C18 column $(250 \times 30 \mathrm{~mm}, 5 \mu \mathrm{m})$.

\subsection{Biological Material}

Ascidian specimens were collected on 11 October 2010, in the Florida Keys $\left(24^{\circ} 37.4873^{\prime}\right.$, $81^{\circ} 27.443^{\prime}$ ). Identification was confirmed by Shirley Parker-Nance. A voucher specimen (FLK10-5-1) for Trididemnum orbiculatum (Van Name, 1902) [12] is housed at the University of Wisconsin-Madison. For cultivation, a sample of ascidian $\left(1 \mathrm{~cm}^{3}\right)$ was rinsed with sterile seawater, macerated using a sterile pestle in a micro-centrifuge tube, and dilutions were made in sterile seawater, with vortexing between steps to separate bacteria from heavier tissues. Dilutions were separately plated on three media: ISP2 supplemented with artificial seawater [21], R2A [22], and M4 [23]. Each medium was supplemented with $50 \mu \mathrm{g} / \mathrm{mL}$ cycloheximide and $25 \mu \mathrm{g} / \mathrm{mL}$ nalidixic acid. Plates were incubated at $28{ }^{\circ} \mathrm{C}$ for at least 28 days, and strain WMMB329 was purified from an M4 isolation plate.

\subsection{Sequencing}

16S rDNA sequencing was conducted as previously described [24]. WMMB329 was identified as a Solwaraspora sp. and demonstrated $99 \%$ sequence similarity to Solwaraspora sp. UMM486 (accession number AY552774) and 99\% sequence similarity to Micromonospora sp. S3-1 (accession 
number AB645957). The 16S sequence for WMMB329 was deposited in GenBank (accession number KC856821).

\subsection{Fermentation, Extraction, and Isolation}

One $10 \mathrm{~mL}$ seed culture $(25 \times 150 \mathrm{~mm}$ tube $)$ in medium modified ASW-A $(5 \mathrm{~g}$ soluble starch, $10 \mathrm{~g}$ glucose, $5 \mathrm{~g}$ peptone, $5 \mathrm{~g}$ yeast extract per liter of $50 \% / 50 \%$ artificial seawater $/ \mathrm{diH}_{2} \mathrm{O}$ ) were inoculated with strain WMMB329 and shaken (200 RPM, $\left.28^{\circ} \mathrm{C}\right)$ for fifteen days. For fermentation, $500 \mathrm{~mL}$ baffled flasks $(2 \times 100 \mathrm{~mL})$ containing ASW-A (20 g soluble starch, $10 \mathrm{~g}$ glucose, $5 \mathrm{~g}$ peptone, $5 \mathrm{~g}$ yeast extract, $5 \mathrm{~g} \mathrm{CaCO}_{3}$ per liter of artificial seawater) were inoculated with $4 \mathrm{~mL}$ seed culture and were incubated $\left(200 \mathrm{RPM}, 28^{\circ} \mathrm{C}\right)$ for fourteen days. Two-liter flasks $(15 \times 500 \mathrm{~mL})$ containing medium ASW-A with Diaion HP20 (7\% by weight) were inoculated with $5 \mathrm{~mL}$ from the $100 \mathrm{~mL}$ culture and shaken $\left(200 \mathrm{RPM}, 28^{\circ} \mathrm{C}\right.$ ) for ten days. Filtered HP20 and cells were washed with $\mathrm{H}_{2} \mathrm{O}$ and extracted with acetone. The acetone extract $(7.1 \mathrm{~g})$ was subjected to liquid-liquid partitioning using $90 \% / 10 \% \mathrm{MeOH} / \mathrm{H}_{2} \mathrm{O}$ and hexanes (1:1) followed by liquid-liquid partitioning of the previous aqueous layer using $70 \% / 30 \% \mathrm{MeOH} / \mathrm{H}_{2} \mathrm{O}$ and $\mathrm{CHCl}_{3}(1: 1)$. The hexanes partition (287 mg) was fractionated by Sephadex LH20 column chromatography $\left(2.5 \times 40 \mathrm{~cm}, \mathrm{CHCl}_{3}: \mathrm{MeOH}, 1: 1\right)$. Fractions containing 1-3 were subjected to RP HPLC (70/30\% to $90 / 10 \% \mathrm{ACN} / \mathrm{H}_{2} \mathrm{O}$ with $\mathrm{H}_{2} \mathrm{O}$ containing $0.1 \%$ acetic acid, $25 \mathrm{~min}, 25 \mathrm{~mL} / \mathrm{min}$ followed by $90 / 10 \%$ to $100 / 0 \%$ of same solvents, $3 \mathrm{~min}, 25 \mathrm{~mL} / \mathrm{min}$, and a hold at $100 / 0 \%$ of same solvents $)$ using a Phenomenex Gemini C18 column $(250 \times 30 \mathrm{~mm}$, $5 \mu \mathrm{m})$, yielding 1 (15.4 mg, $\left.t_{\mathrm{R}} 18.0 \mathrm{~min}\right), 2\left(13.8 \mathrm{mg}, t_{\mathrm{R}} 19.5 \mathrm{~min}\right)$, and $3\left(4.9 \mathrm{mg}, t_{\mathrm{R}} 31.5 \mathrm{~min}\right)$. For ${ }^{13} \mathrm{C}$ incorporation, the same procedure was used with two-liter flasks $(2 \times 500 \mathrm{~mL})$ containing medium ASW-A (U- ${ }^{13} \mathrm{C}$-glucose substituted for unlabeled glucose). Yields for solwaric acids A (1) and (2) were approximately the same during fermentation with $\mathrm{U}^{13} \mathrm{C}$ glucose as with unlabeled glucose.

Solwaric acid A (1). colorless solid; UV (MeOH) $\lambda_{\max }(\log \varepsilon) 204$ (2.77), 218 (2.49), 271 (1.27) nm; IR (ATR) $v_{\max } 2928,2856,1707,1412,1217,994,911,819,755 \mathrm{~cm}^{-1} ;{ }^{1} \mathrm{H}$ and ${ }^{13} \mathrm{C}$ NMR (Table 1); HRMS [M + Na $]^{+} m / z 297.1836$ (calcd. for $\mathrm{C}_{18} \mathrm{H}_{26} \mathrm{O}_{2} \mathrm{Na}^{+}, 297.1825$ ).

Solwaric acid B (2). colorless solid; UV (MeOH) $\lambda_{\max }(\log \varepsilon) 208$ (2.79), 238 (2.48), 281 (1.29) nm; IR (ATR) $v_{\max } 2928,2856,1708,1410,1217,820,755,707,667 \mathrm{~cm}^{-1} ;{ }^{1} \mathrm{H}$ and ${ }^{13} \mathrm{C}$ NMR (Table 1); HRMS [M+Na] $]^{+} m / z 297.1838$ (calcd. for $\mathrm{C}_{18} \mathrm{H}_{26} \mathrm{O}_{2} \mathrm{Na}^{+}, 297.1825$ ).

\subsection{Antibacterial Assay}

Solwaric acid A (1) and B (2) and 2,4,6-triphenyl-1-hexene (3) were tested for antibacterial activity against MSSA (ATCC \#29213), MRSA (ATCC \#33591), E. coli (ATCC \#25922), and P. aeruginosa (ATCC \#27853), and MICs were determined using a dilution antimicrobial susceptibility test for aerobic bacteria [25]. Solwaric acids A (1) and B (2) and 2,4,6-triphenyl-1-hexene (3) were dissolved in DMSO, serially diluted to 10 concentrations $(0.25-128 \mu \mathrm{g} / \mathrm{mL})$, and tested in a 96 -well plate. Vancomycin was used as a control and exhibited an MIC of $1 \mu \mathrm{g} / \mathrm{mL}$ against MSSA and $1 \mu \mathrm{g} / \mathrm{mL}$ against MRSA. Gentamicin was used as a control and exhibited an MIC of $4 \mu \mathrm{g} / \mathrm{mL}$ against E. coli and $4 \mu \mathrm{g} / \mathrm{mL}$ against $P$. aeruginosa. Solwaric acids A (1) and B (2) and 2,4,6-triphenyl-1-hexene (3) were tested in triplicate, and vancomycin and gentamicin was tested in triplicate. Six untreated media 
controls were included on each plate. The plates were incubated at $33{ }^{\circ} \mathrm{C}$ for $18 \mathrm{~h}$. The MIC was determined as the lowest concentration that inhibited visible growth of bacteria.

\section{Conclusions}

We reported the isolation and structure elucidation of two novel trialkyl-substitued aromatic acids, solwaric acids A (1) and B (2), and the known 2,4,6-triphenyl-1-hexene (3). The novel compounds demonstrated antibacterial activity against methicillin-resistant Staphylococcus aureus (MRSA) and methicillin-sensitive Staphylococcus aureus (MSSA). Solwaric acid A (1) and B (2) were enriched with ${ }^{13} \mathrm{C}$-labeled glucose that allowed for the acquisition of a ${ }^{13} \mathrm{C}-{ }^{13} \mathrm{C}$ COSY and unambiguous assignment of the methyl group location on the phenyl ring. While this example utilized ${ }^{13} \mathrm{C}$-labeling to determine carbon connectivity for one challenging portion of the structure, this method could be valuable for molecules with multiple tetrasubstituted centers, which make structure elucidation by standard NMR experiments more challenging. Hence, ${ }^{13} \mathrm{C}$ incorporation and subsequent acquisition of a ${ }^{13} \mathrm{C}-{ }^{13} \mathrm{C}$ COSY - aided by the increasing sensitivity of NMR spectrometers - could drastically reduce the time for structure determination of microbial-derived natural products, including peptides and terpenes. Compared to the cost and time involved with other methods such as computer assisted structure determination, labeling microbial natural products offers a cost effective solution while providing high confidence in the proposed structure.

\section{Acknowledgments}

This work was supported by funding from the University of Wisconsin-Madison School of Pharmacy, the Graduate School at the University of Wisconsin, and the UW College of Agriculture and Life Sciences. This work was also funded by the NIH, NIGMS Grant R01 GM092009 and by R01 GM104192. We would like to thank the Analytical Instrumentation Center at the University of Wisconsin-Madison for the facilities to acquire spectroscopic data, as well as the University of Wisconsin-Madison Chemistry Instrument Center (The purchase of the Waters (Micromass) Autospec $^{\circledR}$ in 1994 was partially funded by NSF Award \#CHE-9304546 to the Department of Chemistry). This study made use of the National Magnetic Resonance Facility at Madison, which is supported by NIH grants P41RR02301 (BRTP/NCRR) and P41GM66326 (NIGMS). Additional equipment was purchased with funds from the University of Wisconsin, the NIH (RR02781, RR08438), the NSF (DMB-8415048, OIA-9977486, BIR-9214394), and the USDA. We would like to thank Don Demaria for assistance with collection and Shirley Parker-Nance for taxonomy.

\section{Conflicts of Interest}

The authors declare no conflict of interest.

\section{References}

1. World Health Organization. Deaths by Cause, Sex, and Mortality Stratum in WHO Regions, Estimates for 2002: World Health Report-2004; World Health Organization: Geneva, Switzerland, 2004; p. 1. 
2. Smith, R.; Coast, J. The true cost of antimicrobial resistance. Br. Med. J. 2013, 346, doi:10.1136/bmj.f1493.

3. Center for Disease Control and Prevention. Available online: http:/www.cdc.gov/drugresistance/ threat-report-2013/ (accessed on 13 December 2013).

4. Boucher, H.W.; Talbot, G.H.; Bradley, J.S.; Edwards, J.E., Jr.; Gilbert, D.; Rice, L.B.; Scheld, M.; Spellberg, B.; Bartlett, J. Bad bugs, no drugs: No ESKAPE! An update from the Infectious Diseases Society of America. Clin. Infect. Dis. 2009, 48, 1-12.

5. Stefani, S.; Chung, D.R.; Lindsay, J.A.; Friedrich, A.W.; Kearns, A.M.; Westh, H.; MacKenzie, F.M. Meticillin-Resistant Staphylococcus aureus (MRSA): Global epidemiology and harmonisation of typing methods. Int. J. Antimicrob. Agents 2012, 39, 273-282.

6. Köck, R.; Becker, K.; Cookson, B.; van Gemert-Pijnen, J.E.; Harbarth, S.; Kluytmans, J.; Mielke, M.; Peters, G.; Skov, R.L.; Struelens, M.J.; et al. Methicillin-Resistant Staphylococcus aureus (MRSA): Burden of disease and control challenges in Europe. Euro Surveill. 2010, 15, 19688-19696.

7. Klevens, R.M.; Morrison, M.A.; Nadle, J.; Petit, S.; Gershman, K.; Ray, S.; Harrison, L.H.; Lynfield, R.; Dumyati, G.; Townes, J.M.; et al. Invasive methicillin-resistant Staphylococcus aureus infections in the United States. JAMA 2007, 298, 1763-1771.

8. de Kraker, M.E.A.; Wolkewitz, M.; Davey, P.G.; Koller, W.; Berger, J.; Nagler, J.; Icket, C.; Kalenic, S.; Horvatic, J.; Seifert, H.; et al. Clinical impact of antimicrobial resistance in European hospitals: Excess mortality and length of hospital stay related to methicillin-resistant Staphylococcus aureus bloodstream infections. Antimicrob. Agents Chemother. 2011, 55, 1598-1605.

9. Staudinger, H.; Steinhofer, A. Über hochpolymere verbindungen. 107. Mitteilung. Beiträge zur kenntnis der polystyrole. Justus Liebigs Ann. Chem. 1935, 517, 35-53.

10. Mayo, F.R. The dimerization of styrene. J. Am. Chem. Soc. 1968, 90, 1289-1295.

11. Ayer, W.A.; Muir, D.J.; Chakravarty, P. Phenolic and other metabolites of Phellinus pini, a fungus pathogenic to pine. Phytochemistry 1996, 42, 1321-1324.

12. Van Name, W.G. The ascidians of the Bermuda Islands. Trans. Connecticut Acad. Sci. 1902, 11, 325-412.

13. Iwata, F.; Sato, S.; Mukai, T.; Yamada, S.; Takeo, J.; Abe, A.; Okita, T.; Kawahara, H. Lorneic acids, trialkyl-substituted aromatic acids from a marine-derived actinomycete. J. Nat. Prod. 2009, 72, 2046-2048.

14. Wenzel, S.C.; Bode, H.B. Novel polyene carboxylic acids from Streptomyces. J. Nat. Prod. 2004, 67, 1631-1633.

15. Mehnaz, S.; Saleem, R.S.; Yameen, B.; Pianet, I.; Schnakenbur, G.; Pietraszkiewicz, H.; Valeriote, F.; Josten, M.; Sahl, H.G.; Franzblau, S.G.; et al. Lahorenoic acids A-C, ortho-dialkyl-substituted aromatic acids from the biocontrol strain Pseudomonas aurantiaca PB-St2. J. Nat. Prod. 2013, 76, 135-141.

16. Raju, R.; Gromyko, O.; Fedorenko, V.; Luzhetskyy, A.; Müller, R. Lorneic acids C and D, new trialkyl-substituted aromatic acids isolated from a terrestrial Streptomyces sp. J. Antibiot. 2013, 66, 347-349.

17. Williams, D.H.; Fleming, I. Spectroscopic Methods in Organic Chemistry, 4th ed.; McGraw-Hill Book Company Limited: London, UK, 1987; pp. 143-146. 
18. Bugni, T.S.; Bernan, V.S.; Greenstein, M.; Janso, J.E.; Maiese, W.M.; Mayne, C.L.; Ireland, C.M. Brocaenols A-C: Novel polyketides from a marine-derived Penicillium brocae. J. Org. Chem. 2003, 68, 2014-2017.

19. Meyer, S.W.; Köck, M. NMR studies of phakellins and isophakellins. J. Nat. Prod. 2008, 71, $1524-1529$.

20. Bifulco, G.; Riccio, R.; Martin, G.E.; Buevich, A.V.; Williamson, R.T. Quantum chemical calculations of ${ }^{1} J_{\mathrm{CC}}$ coupling constants for the stereochemical determination of organic compounds. Org. Lett. 2013, 15, 654-657.

21. Harrison, P.J.; Waters, R.E.; Taylor, F.J.R. A broad spectrum artificial seawater medium for coastal and open ocean phytoplankton. J. Phycol. 1980, 16, 28-35.

22. Reasoner, D.J.; Geldreich, E.E. A new medium for the enumeration and subculture of bacteria from potable water. Appl. Environ. Microbiol. 1985, 49, 1-7.

23. Maldonado, L.A.; Fragoso-Yáñez, D.; Pérez-García, A.; Rosellón-Druker, J.; Quintana, E.T. Antinobacterial diversity from marine sediments collected in Mexico. Antonie Van Leeuwenhoek 2009, 95, 111-120.

24. Wyche, T.P.; Hou, Y.; Braun, D.; Cohen, H.C.; Xiong, M.P.; Bugni, T.S. First natural analogs of the cytotoxic thiodepsipeptide thiocoraline A from a marine Verrucosispora sp. J. Org. Chem. 2011, 76, 6542-6547.

25. National Committee for Clinical Laboratory Standards. Methods for Dilution Antimicrobial Susceptibility Tests for Bacteria that Grow Aerobically, 7th ed.; NCCLS: Villanova, PA, USA, 2006; Approved standard M7-A7.

(C) 2014 by the authors; licensee MDPI, Basel, Switzerland. This article is an open access article distributed under the terms and conditions of the Creative Commons Attribution license (http://creativecommons.org/licenses/by/3.0/). 